\title{
5G AND THE FUTURE OF MOBILITY
}

\section{Chair: Paulo Ricardo Balduino - TVSpectrum Planning Director - Brazilian Radio and TV Broadcasters Association - ABERT}

What is $5 G$ ? ... $5 G$ is the next generation of wireless networks that will provide higher speeds, more capacity and lower latency, will be able to carry billions of connected devices and things, will distribute intelligence! But what does all this mean for users: individuals, companies, governments, researchers, hospitals, public security, etc? What real benefits should be expected from 5G, and when will the different benefits be available in the market? This is the purpose of this panel: explain what is really $5 \mathrm{G}$ and IMT 2020 \& Beyond, addressing mainly the technological, market $\backslash$ economic aspects and the times of the projects.

- Speaker: Lisa Hobbs - Commercial Portfolio Strategy - Compression Solution Area Media - Ericsson

- Speaker: Francisco Giacomini Soares - Senior Director of Regulatory Affairs

- Speaker: Emilio Loures - Director Government and Public Policy - Intel

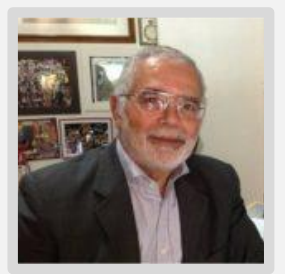

Moderador: Paulo Ricardo Balduino - TV I Spectrum Planning Director - Brazilian Radio and TV Broadcasters Association - ABERT

Paulo Ricardo H. Balduino, born 1949, electronics engineer from the University of Brasília, married, with three children. Oversees the work of the Brazilian Association of Radio and Television Broadcasters - ABERT, focusing on the policy, planning and use of the electromagnetic spectrum. He worked at the Ministry of Communications as coordinator of international regulatory activities in different forums of the International Telecommunications Union - ITU and the Inter-American Telecommunication Commission - CITEL, having created, as far back as 1974 and 1975, the process for Brazil's participation in the work of the ITU and the CITEL, including Brazilian commissions of studies designated at the time as CBR.s and CBTT.s, nowadays restricted and renamed CBC.s. He has headed up Brazilian delegations at several meetings, assemblies and conferences of the ITU and the CITEL on a range of subjects, including planning for the use of the 

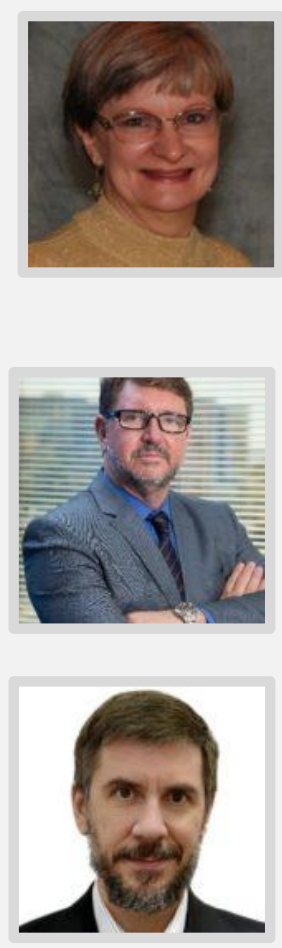

spectrum for different services. When the 12-GHz Satellite Broadcasting Service was in the planning phase, he presided over a group of experts who came up with the planning algorithms and the procedures for updating the plan. He was a founding member of the "National Infrastructure Committee on Information of ANATEL (C.INI - ANATEL), where he was responsible for the Telemedicine Group, having carried out his activities to an advanced level of development. He has represented ANATEL on several forums and working environments on this issue. He was Director and Co-founding Partner of the company, Spectrum Latino America, a joint venture with European company, Spectrum Strategy Consultants

\section{Lisa Hobbs - Commercial Portfolio Strategy - Compression Solution Area Media - Ericsson}

Lisa Hobbs joined Ericsson in 1997 after spending nine years in the satellite communications and video compression divisions of Scientific-Atlanta (now Cisco.) As Vice President, Compression Commercial Portfolio Strategy for Ericsson, she shares global responsibility for defining the direction of the compression portfolio across all of the market segments in which Ericsson has a presence, with a focus on market direction and ROI.

\section{Francisco Giacomini Soares - Senior Director of Regulatory Affairs}

\section{Emilio Loures - Director Government and Public Policy - Intel}

Emilio Loures is Director of Public Policy at Intel in Brazil. Previously led the Brazilian Corporate Affairs team, covering institutional programs in Education and related to the communities we work. In the company since 2001, the executive has worked on broadband and wireless broadband projects at Intel Capital and the Corporate Technology Group. Graduated in Economics from UNICAMP and with a degree in Business Administration from COPPEAD / UFRJ and Fundação Dom Cabral from Belo Horizonte, Emilio was a business planning and development manager at AG Telecom, managing director of Miner Technology Group and a consultant to Monitor / MGDK and Companhia Vale do Rio Doce.

Cite this article:

Balduino, P. R., Hobbs, L., Soares, F. G. and Loures, E.; 2017. 5G and the Future of Mobility. ISSN Print: 2447-0481. ISSN Online: 2447-049X. v.3. doi: 10.18580/setep.2017.42. Web Link: http://dx.doi.org/10.18580/setep.2017.42 